\title{
Reliability and Validity of the Questionnaire for Autism Environment: A pilot survey
}

\author{
Roslinda Ghazali', Siti Rasidah Md Sakip ${ }^{2}$, Ismail Samsuddin ${ }^{3}$ \\ 1 Department of Post-graduate, Faculty of Architecture, Planning \& Surveying, \\ Universiti Teknologi MARA Perak Branch, Seri Iskandar Campus, 32610, Perak, Malaysia. \\ ${ }^{2}$ Department of Landscape Architecture, Faculty of Architecture, Planning \& Surveying, \\ Universiti Teknologi MARA Perak Branch, Seri Iskandar Campus, 32610, Perak, Malaysia \\ ${ }^{2}$ Green Safe Cities Research Group, Universiti Teknologi MARA, Shah Alam Campus,40450, Selangor, Malaysia. \\ ${ }^{3}$ Department of Architecture, Faculty of Architecture, Planning \& Surveying, Universiti Teknologi MARA Perak Branch, \\ Seri Iskandar Campus, 32610, Perak, Malaysia ${ }^{2}$ First affiliation, Organisation, City, Country \\ lindakeruing@gmail.com, sitir704@perak.uitm.edu.my, ismail578@perak.uitm.edu.my \\ 0135185148
}

\begin{abstract}
The increasing numbers of autism give impact to the country, community and family. The only way to help autistic children is to provide them with proper education. Thus, architects play roles in creating responsive buildings. A pilot test has carried out on a group of people similar to the research population. The objective is to assess the reliability and validity of a questionnaire. Four sections (144 items) determining the frequency of Sensory Sensitivity, Sensory Stimulation, Sensory Design and Physical Learning Environment. Respondent $(\mathrm{N}=35)$ completed the survey and the reliability test resultant to reveal inconsistencies and revising the criteria accordingly.

Keywords: Autism; validity; reliability; pilot test;

eISSN: 2398-4287@ 2020. The Authors. Published for AMER ABRA cE-Bs by e-International Publishing House, Ltd., UK. This is an open access article under the CC BYNC-ND license (http://creativecommons.org/licenses/by-nc-nd/4.0). Peer-review under responsibility of AMER (Association of Malaysian Environment-Behaviour Researchers), ABRA (Association of Behavioural Researchers on Asians) and cE-Bs (Centre for Environment-Behaviour Studies), Faculty of Architecture, Planning \& Surveying, Universiti Teknologi MARA, Malaysia. DOI: https://doi.org/10.21834/ebpj.v5i15.2470.
\end{abstract}

\subsection{Introduction}

The United States revealed the most recent data that as many as one in every 68 children had diagnosed with ASD. While in Malaysia, the number of individuals with autism has been increasing at three per cent per year. The increasing numbers give impact to the country, community and family. The only way to help autistic children is to provide them with proper education. Unfortunately, the learning environment does not accommodate their complex condition to overcome their needs. In this situation, architects play roles in creating responsive buildings. However, they have limited knowledge and lack of awareness in terms of the sensory environment for people with autism. The objective is to assess the validity and reliability of a questionnaire designed to measure knowledge and awareness among who involves in the autism learning environment. Questionnaire content determined by gaps highlighted in a literature review. We aim to test the internal consistency and content validity of an instrument designed, face validity, item analysis, repeat and internal reliability assessed. Four sections (144 items) determining the frequency of Sensory Sensitivity, Sensory Stimulation, Sensory Design and Physical Learning Environment. Appointed experts $(\mathrm{N}=9)$ completed detailed content validity assessment, resulting scores for appropriateness, the phrasing of questions, grammar and proofreading suggested by the expert. Perhaps the outcome would give

eISSN: 2398-4287C 2020. The Authors. Published for AMER ABRA cE-Bs by e-International Publishing House, Ltd., UK. This is an open access article under the CC BYNC-ND license (http://creativecommons.org/licenses/by-nc-nd/4.0/). Peer-review under responsibility of AMER (Association of Malaysian Environment-Behaviour Researchers), ABRA (Association of Behavioural Researchers on Asians) and cE-Bs (Centre for Environment-Behaviour Studies), Faculty of Architecture, Planning \& Surveying, Universiti Teknologi MARA, Malaysia.

DOI: https://doi.org/10.21834/ebpj.v5i15.2470 
beneficial for a designer to create spaces for autistic, accommodate the specific sensory needs, creating a conducive environment and help the development of the autistic child in the future.

\subsection{Literature Review}

This section elaborated the key concept of the autistic children experiences the unusual sensory. The key concept comprises of Sensory Sensitivity, Sensory Stimulation, Sensory Design and Physical Learning Environment.

The first key concept is Sensory Sensitivity occurs a variety with the two most common sensory patterns being hyper and hypo responsivity (hyper-sensitive and hypo-sensitive). Hypersensitive means are over-responsive to sensory stimuli, which can be easily overwhelmed with the environment that frightening at times. Such as loud or sudden noises that would make them feel physically pain stressful (Gaines et al., 2016). Hyposensitive means under-responsive as if certain sensory information goes unnoticed or certain senses are impaired (Gaines et al., 2016). Children who diagnosed had hyposensitive with auditory tendencies were often thought to be deaf. Hyposensitive are often qualified as "sensory-seeking," meaning they often create or generate their own sensory experiences either for pleasure or to block out other unpleasant stimuli (Gaines et al., 2016).

The Sensory Stimulation is related to unusual responses regarding acoustic, colour, smell, lighting and visual. Autistic may experience a completely different set of responses to a given stimulus than children who do not have autism (Liss Radunovich \& Kochert, 2014). The setting for the learning environment should consider the sensory issues to overcome their needs and to help them to continue their lives and exhibit normal development (Beaver, 2006). According to Ghazali et al. (2019a), the fluorescent lights does not provide the best quality of light for learning especially for autistic children. However, the lighting can improve student comfort and attention, natural lighting is to ensure good general lighting for the entire space without the flickering lights or dark corners. Unlike the regular classroom that designed to stimulate the students, space designed to reduce sensory Stimulation (Hebert, 2003). Besides, Hebert (2003) mentioned that the painted wall soothing colours and free of busy bulletin boards. The lighting, rather than fluorescent, was soft and free from hanging mobiles and artwork. Space highly organized, and all materials were in the proper place and accessible to the child, encouraging independence.

The Sensory Design beneficial to the autism learning environment. The Sensory Design is design for living which how space feels, sounds, looks, smells and functions can be incredibly affecting one or more of the seven senses which can have an overwhelming effect on their life (Society, 2015). Their senses can be either over-developed (hypersensitive) or under-developed (hyposensitive) which can result in feelings of anxiety, stress \& occasionally, physical pain (Ghazali et al., 2018). Research done by Paron-Wildes (2005) explained that when designing children's environments, it is essential to consider the needs of children with neurological disorders and to think through space as an experience. He explored with individuals suffering from problems with sensory integration or sensory defensiveness and revealed that autistic does not typically fall in the "normal" or "average" range of sensory values that they experienced.

The Physical Learning Environment refers to the space allocated for classrooms, science labs, open spaces and offices (Amirul, Che Ahmad, Yahya, Lee Abdullah, Adnan and Mohamed Noh, 2013). They defined the learning environment as the social context, psychological and pedagogical, which can affect learning, achievement and attitudes of the students. Research done by Shaari \& Ahmad (2016) proved that there is a link between the physical learning environment and children school readiness. Therefore, the importance of the physical learning environment can no longer be ignored. They suggested that quality and adequately designed physical learning environment will boost the development and education of children as well as contributing to improved school readiness among children and a better education system. Not only sensory sensitivity, sensory stimulation and sensory design, the designer should consider physical learning environment which it is the most potential that easily triggers the anxiety among autistic (Ghazali, Md Sakip, et al., 2019b). Hence, ensuring that school children are ready is essential when designing a school.

\subsection{Methodology}

The pilot study is a practice whereby the researchers would test the research instrument that has been developed before its actual use to ascertain the likely problems with it (Kothari et al., 2014). The purpose is not to collect data but to identify issues that the potential respondents might have in either understanding or interpreting a question. The researchers are to identify if there are problems in understanding the way an item has worded, the appropriateness of the meaning it communicates, whether different respondents interpret a question differently, and to establish whether their interpretation is different to what you were trying to convey. If there are problems researcher need to re-examine the wording to make it more precise and unambiguous (Kothari et al., 2014).

The objective of this paper is to identify the measurement of the SynDLe (Sensory Sensitivity, Sensory stimulation, Sensory Design and Physical Learning Environment) components. Before the questionnaire distributed, the researcher refers to the expertise to check the quality of the questionnaire. Then, corrections of the questionnaire need to made according to feedback from the checking of the questionnaire. After the final questionnaire drafted and confirmed, it can be printed and sent out to the respondents for data collection.

\subsection{Questionnaire Development}

The task of developing a questionnaire is the greatest challenge perhaps is to come up with a questionnaire that is psychometrically sound, and is efficient and effective for use in research (Tsang et al., 2019). The questionnaire-based on four key concept (SynDLe) Sensory Sensitivity, Sensory Stimulation, Sensory Design and Physical Learning Environment. This key concept creates from researcher's experiences during the preliminary study and the extensive literature on autism environment. The questionnaire designed 
to close-ended and self-administered by the respondent. A pilot test has carried out under actual field conditions on a group of people similar to the research population.

\subsection{Sampling}

The respondents that involved in this pilot study were architects within the government technical agency due to their significant role in designing a building and interventionist attach to Autism Centre that facilitates by the government. Radhakrishna (2007), Bolarinwa (2015) and Munir (2018) mentioned that the sample size acceptable for a preliminary research is suggested established using a pilot test by collecting data from 20 to 30 respondents. Therefore, the pilot study conducted on thirty-five (35) respondents that had an experience involved with a physical learning environment for autism and the pilot study took about three months for the respondent to respond the questionnaire.

\subsection{Measurement}

The measurement design of the SynDLe components based on the extensive review of previous literature that is relevant to the SynDLe components. The questionnaire consists of seven (7) sections, and this explained as follows:

Section 1 - Information sheet.

Section 2 - Instruction for rating measure.

Section 3 - Demographic information.

Section 4 - Sensory Sensitivity among the items are sight, sound, smell, taste, touch, proprioception and Vestibular.

Section 5 - Sensory Stimulation involving the items acoustic, colour, smell, lighting and visual.

Section 6 - Sensory Design among the items are acoustic, spatial sequencing, escape space, compartmentation, transition zone, sensory zoning, safety and security.

Section 7 - Physical Learning Environment comprises of building scale, accessibility, wayfinding, toilet provision, window, ventilation/heating, threshold, legibility and furniture.

All of these SynDLe components were measured using a 5-point Likert Scale of 1 - strongly disagree, 2 - disagree, 3 - not sure, 4 agree and 5 - strongly agree.

\subsection{Procedures}

Towards achieving the objective, 35 respondents randomly selected from the government technical agency and the Autism Centre. Participation will involve completing the questionnaire via the electronic link provided. The researchers introduced themselves as well as explaining the purpose of the study undertaken, before the researcher asking the respondents to answer the questionnaire. They are given one week to respond to the survey, and the following week the researchers followed up the respondent individually. The researchers undergo this survey via the electronic survey due to the global pandemic covid-19. The pilot study took about three months for the respondent to respond to the questionnaire.

\subsection{Limitations}

During the pilot test, the researchers had difficulty in approaching the respondent to take part in the survey. This is due to the data collection period that took place during the pandemic Covid-19. The researcher used the electronic as such an email and online survey to conduct the pilot test. However, some respondents are more interested in meeting with researchers to respond to the questionnaire. The reason being of too many questions and lengthy question makes the respondent not interested in taking part.

\subsection{Findings}

This pilot study involved more female respondents $(77.1 \%)$ as compared to male respondents $(22.9 \%)$ with most of the respondents being in the 20 to 30 years old and 40 to 50 years old age range group (both range group at $37.1 \%$ ). A large group of respondents were from the government technical agency (51\%) as compared to the Autism Centre (49\%). Among the respondent, only a small respondent who awarded as Professional Architect (11\%), and others yet obtained a professional architect and not applicable ( $89 \%)$. The majority $40 \%$ of the participants had less than five years' service duration. However, most of the respondent interested in autism design, even among them have no children or family member with autism $(74.3 \%)$.

The pilot test that conducted to identify the reliability and validity, the items for each Sensory Sensitivity (SSy), Sensory Stimulation (SSn), Sensory Design (SD) and Physical Learning Environment (PLE) (SynDLe) dimension were measured using the Cronbach alpha (a) analysis. The reliability refers to the ability of a questionnaire to consistently measure an attribute and how well conceptually the items fit together (Ghorashi et al., 2016). A value of around 0.70 or greater widely considered desirable values even when an instrument is exploring multiple constructs or testing for several different aspects of knowledge or understanding (Taber, 2018). Therefore, the analysis of the pilot test showed the validity measurement that the concerned construct of a conducive environment for autism as the a value $=0.90$ (Sensory Sensitivity), 0.93 (Sensory Stimulation), 0.97 (sensory Design) and 0.97 (physical learning environment) as shown in Table 1.

Table 1. Reliability Statistic for each Variables.

\begin{tabular}{ccc}
\hline Variables & Cronbach's Alpha & Number of Items \\
\hline Sensory Sensitivity & 0.90 & 35 \\
Sensory Stimulation & 0.93 & 27
\end{tabular}




\begin{tabular}{lrr} 
Sensory Design & 0.97 & 37 \\
Physical Learning Environment & 0.97 & 45 \\
\hline (Source: SPSS Generated)
\end{tabular}

From the aspect of validity, an item-to-scale value of 0.3 and above used as the minimum value for a unidimensional scale while the scale considered reliable if the alpha value was 0.6 and above (Rahman \& Md Sakip, 2015). As a result of testing validity and reliability, unaccepted values below $\alpha=0.3$ eliminated and this process repeated until the questionnaire meets the standards set by the researcher or above the value $\mathrm{a}=0.3$ to ensure that the content validity not jeopardized (Del Greco et al., 1987). Therefore, the piloting tested, and there are 14 items from the questionnaire eliminated because of a corrected item-to-total correlation value is below 0.3 (Rahman \& Md Sakip, 2015).

\subsection{Discussion}

The internal reliability of the thirty-five (35) items Sensory Sensitivity (SSy) scale investigated using Cronbach's alpha. As mentioned by Del Greco et al. (1987), an item-to-scale above the value $\alpha=0.3$ to ensure that the content validity not jeopardized. Results indicated that the alpha for the total scale was equal to 0.891 . However, the researchers examined individual item statistics and suggested that elimination of several items would increase the reliability of the scale. Subsequent analyses indicated that alpha could improve after eliminating each of the following items individually: "SSy1-The design of the window should provide at a high level for the autistic classroom", "SSy4-The dimmers help to adjust lighting levels", "SSy5-Or the autistic classroom should not have windows", "SSy9-The dining area can be stressful for the autistic children", "SSy11-The autistic classroom to be located far from the dining area", and "SSy13The toilet to be located far from the autistic classroom.". The final reliability for the resulting six-item scale considered acceptable, $a=$ 0.90 as shown in Table 2.

Table 2. Sensory Sensitivity (Reliability and Validity Test)

\begin{tabular}{|c|c|c|c|c|}
\hline Variables & Dimension & Code & $\begin{array}{l}\text { Corrected Item- } \\
\text { Total Correlation }\end{array}$ & $\begin{array}{c}\text { (Reliability) } \\
\text { Cronbach's Alpha }\end{array}$ \\
\hline \multirow{35}{*}{$\begin{array}{l}\text { Sensory } \\
\text { Sensitivity }\end{array}$} & \multirow[t]{5}{*}{ Sight } & SSy1 & - & \multirow{35}{*}{0.90} \\
\hline & & SSy2 & .463 & \\
\hline & & SSy3 & .373 & \\
\hline & & SSy4 & - & \\
\hline & & SSy5 & - & \\
\hline & \multirow[t]{5}{*}{ Sound } & SSy6 & .390 & \\
\hline & & SSy7 & .493 & \\
\hline & & SSy8 & .461 & \\
\hline & & SSy9 & - & \\
\hline & & SSy10 & .338 & \\
\hline & \multirow[t]{5}{*}{ Smell } & SSy11 & - & \\
\hline & & SSy12 & .575 & \\
\hline & & SSy13 & - & \\
\hline & & SSy14 & .514 & \\
\hline & & SSy15 & .622 & \\
\hline & \multirow[t]{5}{*}{ Taste } & SSy16 & .497 & \\
\hline & & SSy17 & .449 & \\
\hline & & SSy18 & .494 & \\
\hline & & SSy19 & .417 & \\
\hline & & SSy20 & .329 & \\
\hline & Tactile & SSy21 & .561 & \\
\hline & \multirow{4}{*}{$\begin{array}{l}\text { Sensation } \\
\text { (Touch) }\end{array}$} & SSy22 & .474 & \\
\hline & & SSy23 & .710 & \\
\hline & & SSy24 & .410 & \\
\hline & & SSy25 & .420 & \\
\hline & \multirow{5}{*}{$\begin{array}{l}\text { Proprio- } \\
\text { ception (The } \\
\text { sense of } \\
\text { position) }\end{array}$} & SSy26 & .506 & \\
\hline & & SSy27 & .697 & \\
\hline & & SSy28 & .306 & \\
\hline & & SSy29 & .512 & \\
\hline & & SSy30 & .522 & \\
\hline & \multirow{5}{*}{$\begin{array}{l}\text { Vestibular } \\
\text { (The sense of } \\
\text { balance }\end{array}$} & SSy31 & .491 & \\
\hline & & SSy32 & .504 & \\
\hline & & SSy33 & .616 & \\
\hline & & SSy34 & .329 & \\
\hline & & SSy35 & .493 & \\
\hline
\end{tabular}


Results for the Sensory Stimulation (SSn) showed that the alpha for the total scale was equal to 0.91. As mention by Taber (2018), the alpha 0.91 is a strong value; however, the researcher examined the individual item statistics and found five (5) item at below 0.3 among twenty-seven (27) items of Sensory Stimulation. The weak value suggested to eliminate individually, and the value increases to the reliability scale (Del Greco et al., 1987). Subsequent analyses indicated that alpha could improve after eliminating each of the following items individually: "SSn46-The softer or calming colour in light pink is suited for an autistic classroom" (reverse-scored), "SSn47-The softer or calming colour in pale yellow is suited for an autistic classroom ", "SSn56-The designers to allocate windows at a low level in the classroom.", "SSn58-A student's artwork may distract autistic attention.", and "SSn59-A student's artwork on the bulletin board may affect autistic behaviour." The final reliability for the resulting five-item scale was increased and considered acceptable, $a=$ 0.93 As shown in Table 3.

Table 3. Sensory Stimulation (Reliability and Validity Test)

\begin{tabular}{|c|c|c|c|c|}
\hline Variables & Dimension & Code & $\begin{array}{l}\text { Corrected Item- } \\
\text { Total Correlation }\end{array}$ & $\begin{array}{c}\text { (Reliability) } \\
\text { Cronbach's Alpha }\end{array}$ \\
\hline Sensory & Sound (The & SSn36 & .473 & \\
\hline \multirow[t]{26}{*}{ Stimulation } & sense of & $\operatorname{SSn} 37$ & .661 & 0.93 \\
\hline & hearing) & SSn38 & .518 & \\
\hline & & SSn39 & .752 & \\
\hline & & SSn 40 & .466 & \\
\hline & Colour & SSn41 & .690 & \\
\hline & & SSn42 & .561 & \\
\hline & & SSn43 & .734 & \\
\hline & & SSn44 & .412 & \\
\hline & & SSn45 & .529 & \\
\hline & & SSn46 & - & \\
\hline & & SSn47 & - & \\
\hline & Smell & SSn48 & .722 & \\
\hline & & SSn 49 & .725 & \\
\hline & & SSn50 & .752 & \\
\hline & & SSn51 & .726 & \\
\hline & & SSn52 & .631 & \\
\hline & Lighting & SSn53 & .690 & \\
\hline & & SSn54 & .674 & \\
\hline & & SSn55 & .568 & \\
\hline & & SSn56 & - & \\
\hline & & SSn57 & .310 & \\
\hline & Visual & SSn58 & - & \\
\hline & & SSn59 & - & \\
\hline & & SSn60 & .442 & \\
\hline & & SSn61 & .517 & \\
\hline & & SSn62 & .487 & \\
\hline
\end{tabular}

The internal reliability of the thirty-seven (37) items reliability results for Sensory Design (SD) questionnaire are values ranging from 0.215 (not satisfactory) to 0.859 (reliable). Results indicated that the alpha for the total scale was equal to 0.966 . The researcher examined each item statistics and suggested to eliminate two (2) items. Subsequent analyses indicated that alpha could be increased the reliability of the scale and improved after eliminating each of the following items individually such as: "SD80-Separate spaces using the furniture will organize the area." and "SD82-Separate spaces using a floor covering such as a carpet or a floor mat will organize the area.". The final reliability was considered acceptable with the $a=0.968$ as shown in Table 4.

Table 4. Sensory Design (Reliability and Validity Test)

\begin{tabular}{|c|c|c|c|c|}
\hline Variables & Dimension & Code & $\begin{array}{l}\text { Corrected Item- } \\
\text { Total Correlation }\end{array}$ & $\begin{array}{c}\text { (Reliability) } \\
\text { Cronbach's Alpha }\end{array}$ \\
\hline \multirow[t]{13}{*}{ Sensory Design } & Acoustic & SD63 & .486 & \multirow{6}{*}{0.97} \\
\hline & & SD64 & .744 & \\
\hline & & SD65 & .744 & \\
\hline & & SD66 & .740 & \\
\hline & & SD67 & .753 & \\
\hline & & SD68 & .799 & \\
\hline & Spatial & SD69 & .793 & \\
\hline & \multirow[t]{4}{*}{ Sequencing } & SD70 & .815 & \\
\hline & & SD71 & .741 & \\
\hline & & SD72 & .707 & \\
\hline & & SD73 & .541 & \\
\hline & \multirow[t]{2}{*}{ Escape Space } & SD74 & .668 & \\
\hline & & SD75 & .758 & \\
\hline
\end{tabular}




\begin{tabular}{lccc} 
& & & \\
& & SD76 & .626 \\
\cline { 3 - 3 } Compart- & SD77 & .678 \\
mentation & SD78 & .551 \\
& SD79 & .322 \\
& SD80 & - \\
& SD81 & .617 \\
& SD82 & - \\
Transition & SD83 & .521 \\
Zone & SD84 & .627 \\
& SD85 & .758 \\
& SD86 & .309 \\
& SD87 & .589 \\
Sensory & SD88 & .755 \\
Zoning & SD89 & .768 \\
& SD90 & .709 \\
& SD91 & .792 \\
& SD92 & .706 \\
Safety and & SD93 & .688 \\
Security & SD94 & .857 \\
& SD95 & .859 \\
& SD96 & .544 \\
& SD97 & .736 \\
& SD98 & .763 \\
& SD99 & .823 \\
\hline
\end{tabular}

Note: (-) deleted item shows the item-to-total correlation value is below 0.3 .

(Source: SPSS Generated)

The internal reliability of the forty-five (45) items Physical Learning Environment (PLE) Scale was investigated, and the researcher found that only one (1) item is below 0.3. The elimination increases the value from $\alpha=0.965$ to $\alpha=0.966$. The item that eliminated from the questionnaire is "PLE123-Provides windows at a low level in the classroom" ( $\alpha=0.261$ - not satisfactory). Subsequent, analyses indicated that the final reliability was considered acceptable with the $\alpha=0.966$ as shown in Table 5 .

Table 5. Physical Learning Environment (Reliability and Validity Test)

\begin{tabular}{|c|c|c|c|c|}
\hline Variables & Dimension & Code & $\begin{array}{l}\text { Corrected Item- } \\
\text { Total Correlation }\end{array}$ & $\begin{array}{c}\text { (Reliability) } \\
\text { Cronbach's Alpha }\end{array}$ \\
\hline \multirow{31}{*}{$\begin{array}{l}\text { Physical } \\
\text { Learning } \\
\text { Environment }\end{array}$} & Building Scale & PLE100 & .392 & \multirow{31}{*}{0.97} \\
\hline & & PLE101 & .811 & \\
\hline & & PLE102 & .592 & \\
\hline & & PLE103 & .413 & \\
\hline & & PLE104 & .370 & \\
\hline & Access & PLE105 & .678 & \\
\hline & & PLE106 & .675 & \\
\hline & & PLE107 & .786 & \\
\hline & & PLE108 & .802 & \\
\hline & & PLE109 & .678 & \\
\hline & Way-finding & PLE110 & .806 & \\
\hline & & PLE111 & .807 & \\
\hline & & PLE112 & .533 & \\
\hline & & PLE113 & .756 & \\
\hline & & PLE114 & .799 & \\
\hline & Toilet & PLE115 & .823 & \\
\hline & & PLE116 & .562 & \\
\hline & & PLE117 & .536 & \\
\hline & & PLE118 & .693 & \\
\hline & & PLE119 & .350 & \\
\hline & Window & PLE120 & .483 & \\
\hline & & PLE121 & .658 & \\
\hline & & PLE122 & .682 & \\
\hline & & PLE123 & - & \\
\hline & & PLE124 & .325 & \\
\hline & Ventilation & PLE125 & .404 & \\
\hline & & PLE126 & .525 & \\
\hline & & PLE127 & .812 & \\
\hline & & PLE128 & .567 & \\
\hline & & PLE129 & .690 & \\
\hline & & PLE130 & .733 & \\
\hline
\end{tabular}




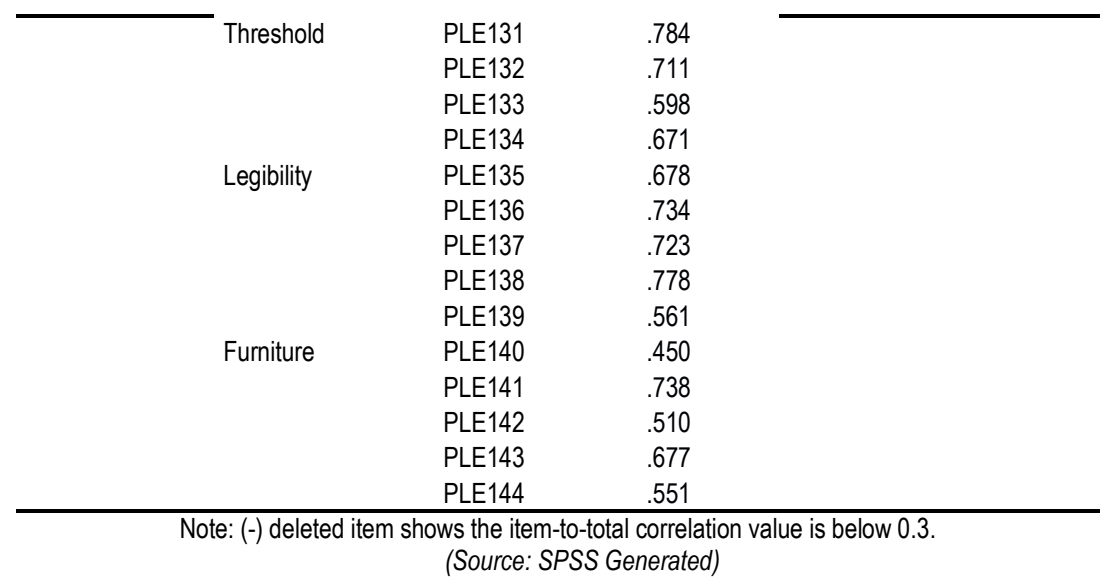

\subsection{Conclusion and Recommendation}

According to Mohajan (2017), the better the reliability is performed, the more accurate the results; which increases the chance of making correct decision in research. Overall, the questionnaire is a suitable tool to evaluate knowledge and awareness among who involves in the autism learning environment. This study proved to be a valid and reliable tool before it utilized in the actual fieldwork. A pilot study is important to observe any potential improvement in the questionnaire designed by the researcher. The researcher aims to formulate questions that are appropriate and encompass of all information that is essential for the study. This is to ensure that the respondent understands the question better after correction.

The researchers revising and modified the sentence as commented by the expert, and the researchers restructure the numbering of the questionnaire. This is the strategy taken to avoid bored among respondents when answering the questions. The dimension in the components of SynDLe eliminated from the questionnaire. This is due to the item showed a weak value among the items. Through observation, the researchers found that the items are weak because the question was unclear and redundant in terms of measuring the subject matter. The questionnaire showed the perfect test-retest reliability among who involves in the autism learning environment. the final questionnaire is an instrument for assessing respondents and valid to be used to measure the concerned construct of conducive environment for autism. Hence, the researchers assured that the results are valid and reliable for further studies.

Further research should involve examining other questionnaire administration methods in various settings. The next stage is to collect data in the actual fieldwork. The researcher using theoretical or conceptual framework in the study, hence, the relationship with the findings should be explored. Exploratory data analysis (EFA) to interpret or inferences drawn should be clearly identified as such and consistent with the results.

\section{Acknowledgements}

I would like to thank my supervisor Dr Siti Rasidah Md Sakip and Asso. Prof. Dr Ismail Samsuddin for supporting me. Also, I would thank Jabatan Kerja Raya Malaysia for allowing me to further my study.

\section{Paper Contribution to Related Field of Study}

Particular attention is paid towards the careful development of questionnaire for respondent to be involved. The study expected to support the greater goal of improving the learning environment of autistic. The proposed framework would help designers informing the scope and brief before they develop their design. It is hoped that the designers can take it from understandings of 'other' perspective on the built environment. The conducive learning environment ultimately help autistic to focus during their learning process, although having different abilities.

\section{References}

Amirul, N. J., Nidzam, C., Ahmad, C., Yahya, A., Faizal, M., Abdullah, N. L., Adnan, M., \& Noh, N. M. (2013). The physical classroom learning environment. 2nd International Higher Education Teaching and Learning Conference 2013, 9 pages.

Beaver, C. (2006). Designing Environments for Children \& Adults with ASD. In Autism Safari 2006 2nd World Autism Congress \& Exhibition.

Bolarinwa, O. (2015). Principles and methods of validity and reliability testing of questionnaires used in social and health science researches. Nigerian Postgraduate Medical Journal, 22(4), 195. https://doi.org/10.4103/1117-1936.173959

Del Greco, L., Walop, W., \& McCarthy, R. H. (1987). Questionnaire development: 2. Validity and reliability. Canadian Medical Association Journal, 136(7), 699-700. Gaines, K., Bourne, A., Pearson, M., \& Kleibrink, M. (2016). Designing for Autism Spectrum Disorders. Routledge Taylor \& Francis Group. https://doi.org/10.4324/9781315856872 
Ghazali, R., Md. Sakip, S. R., \& Samsuddin, I. (2019). Sensory Design of Learning Environment for Autism : Architects awareness? Journal of ASIAN Behavioural Studies, 4(14), 53-62. https://doi.org/10.21834/jabs.v4i14.338

Ghazali, R., Md Sakip, S. R., \& Samsuddin, I. (2018). A Review of Sensory Design Physical Learning Environment for Autism Centre. E-IPH, AicQoL2018Perhentianlsland, 3(7), 7 pages.

Ghazali, R., Md Sakip, S. R., \& Samsuddin, I. (2019). Creating Positive Environment for Autism Using Sensory Design. Environment-Behaviour Proceedings Journal, 4(10), 19. https://doi.org/10.21834/e-bpj.v4i10.1618

Ghorashi, Z., yousefy, A., \& merghati-khoei, E. (2016). Developing and validating a questionnaire to measure women's sexual behaviors: A psychometric process. Galen Medical Journal, 5(4), 208-214.

Hebert, B. B. (2003). Design Guidelines of a Therapeutic Garden for Autistic Children (Issue May). Louisiana State University.

Kothari, C., Kumar, R., \& Uusitalo, O. (2014). Research Methodology. In New Age International.

https://doi.org/http://196.29.172.66:8080/jspui/bitstream/123456789/2574/1/Research\%20Methodology.pdf

Liss Radunovich, H., \& Kochert, J. L. (2014). Creating a Successful Early Learning Environment for Children Who Have Autism Spectrum Disorders 1 What Are Autism Spectrum Disorders? IFAS Extension, 1-6.

Mohajan, H. K. (2017). Two Criteria for Good Measurements in Research: Validity and Reliability. Annals of Spiru Haret University. Economic Series, 17(4), 59-82. https://doi.org/10.26458/1746

Munir, F. F. A. (2018). Reliability and Validity Analysis on the Relationship between Learning Space, Studentânıs Satisfaction and Perceived Performance Using SMART-PLS. International Journal of Academic Research in Business and Social Sciences, 8(1), 772-783. https://doi.org/10.6007/ijarbss/v8-i1/3847

Paron-Wildes, A. J. (2005). Sensory Stimulation and Autistic Children. Implications, 06(04), 1-5.

Radhakrishna, R. B. (2007). Tips for Developing and Testing Questionnaires / Instrumen Step 1--Background Step 2--Questionnaire Conceptualization. Journal of Extension, 45(1), Online. http://www.joe.org/joe/2007february/tt2.php

Rahman, N. A., \& Md Sakip, S. R. (2015). Relationship between accessibility and safety criterias with the uses of the street: A case study of urban commercial street in Kuala Lumpur city centre. Advances in Environmental Biology, 9(5), 47-49.

Shaari, M. F., \& Ahmad, S. S. (2016). Physical Learning Environment: Impact on Children School Readiness in Malaysian Preschools. Procedia - Social and Behavioral Sciences, 222, 9-18. https://doi.org/10.1016/j.sbspro.2016.05.164

Society, T. N. A. (2015). Autism Friendly Design. Your Autism Magazine, 49(2), 513600-513600. http://www.autism.org.uk/professionals/others/architects/autismfriendly-design.aspx

Taber, K. S. (2018). The Use of Cronbach's Alpha When Developing and Reporting Research Instruments in Science Education. Research in Science Education, 48(6), 1273-1296. https://doi.org/10.1007/s11165-016-9602-2

Tsang, S., Royse, C. F., \& Terkawi, A. S. (2019). Guidelines for developing , translating , and validating a questionnaire in perioperative and pain medicine. 11(Suppl 1), 1-15. https://doi.org/10.4103/sja.SJA 